\title{
Evaluation of Partial Pressure of Arterial Oxygen in Obese Patients in Supine Position during General Anesthesia
}

\author{
Kenichi Satoh $^{1 *}$, Mami Chikuda1, Ayako Ohashi', Miho Kumagai², Akiyoshi Kuji², \\ Shigeharu Joh'1 \\ ${ }^{1}$ Division of Dental Anesthesiology, Department of Reconstructive Oral and Maxillofacial Surgery, School of \\ Dentistry, Iwate Medical University, Morioka, Japan \\ ${ }^{2}$ Division of Special Care Dentistry, Department of Developmental Oral Health Science, School of Dentistry, \\ Iwate Medical University, Morioka, Japan \\ Email: satoken@iwate-med.ac.jp
}

Received 1 April 2015; accepted 8 May 2015; published 13 May 2015

Copyright (C) 2015 by authors and Scientific Research Publishing Inc.

This work is licensed under the Creative Commons Attribution International License (CC BY).

http://creativecommons.org/licenses/by/4.0/

c) (i) Open Access

\section{Abstract}

Background: Anesthetists should measure the concentration of supplemental oxygen to determine whether patients' partial pressure of arterial oxygen $\left(\mathrm{PaO}_{2}\right)$ is correct during general anesthesia. However, the standard $\mathrm{PaO}_{2}$ value in obese patients in the supine position is unknown. We evaluated the $\mathrm{PaO}_{2}$ with respect to the Broca-Katsura obesity index. Materials and Methods: From January 2001 to December 2013, we evaluated 472 patients aged $\geq 16$ years old that underwent general anesthesia in the supine position. The anesthetic charts of 472 patients with an American Society of Anesthesiologists physical status of I or II were retrospectively reviewed to investigate the $\mathrm{PaO}_{2}$. Results: In patients aged 16 to $<65$ years old, the $\mathrm{PaO}_{2}$ was $165.7 \pm 25.6 \mathrm{mmHg}$ at a Broca-Kat- sura index of $<20 \%, 141.8 \pm 26.9 \mathrm{mmHg}$ at a Broca-Katsura index of $20 \%$ to $<40 \%, 132.7 \pm$ $22.7 \mathrm{mmHg}$ at a Broca-Katsura index of $40 \%$ to $<60 \%$, and $111.7 \pm 34.6 \mathrm{mmHg}$ at a Broca-Katsura index of $\geq 60 \%$. In patients aged 65 to $<84$ years old, the $\mathrm{PaO}_{2}$ was $152.1 \pm 23.8 \mathrm{mmHg}$ at a Broca-Katsura index of $<20 \%, 130.6 \pm 26.7 \mathrm{mmHg}$ at a Broca-Katsura index of $20 \%$ to $<40 \%$, and $127.5 \pm 11.3 \mathrm{mmHg}$ at a Broca-Katsura index of $40 \%$ to $<60 \%$. Conclusion: With an increasing Broca-Katsura index, the $\mathrm{PaO}_{2}$ tended to decrease with age from 16 to $<65$ years old and 65 to $<84$ years old. Additionally, the $\mathrm{PaO}_{2}$ tended to decrease with age from 16 to $<65$ years at a BrocaKatsura index of $20 \%$ to $<40 \%$.

\section{Keywords}

Arterial Partial Pressure of Oxygen, Broca-Katsura Index, General Anesthesia, Obesity, Supine

\footnotetext{
"Corresponding author.
}

How to cite this paper: Satoh, K., Chikuda, M., Ohashi, A., Kumagai, M., Kuji, A. and Joh, S. (2015) Evaluation of Partial Pressure of Arterial Oxygen in Obese Patients in Supine Position during General Anesthesia. Open Journal of Anesthesiology, 5, 85-92. http://dx.doi.org/10.4236/ojanes.2015.55017 


\section{Position}

\section{Introduction}

Anesthetic management is reportedly associated with a higher incidence of critical incidents during anesthesia in obese than in nonobese patients [1]. During general anesthesia, obese patients are more likely to develop rapid oxygen desaturation during periods of apnea [2] and exhibit lower tissue oxygen levels at a given partial pressure of arterial oxygen $\left(\mathrm{PaO}_{2}\right)$ than that of nonobese patients [3]. Additionally, in patients in the supine position, general anesthesia induces atelectasis formation, a reduction in lung volume, and respiratory mechanical impairment that may be associated with gas exchange abnormalities [4]. An increase in the intra-abdominal pressure and consequent cephalad displacement of the diaphragm caused by the anesthetic procedure account for the occurrence of atelectasis in the most dependent lung regions and are associated with oxygenation impairment after anesthetic induction [5] [6]. Anesthesia may thus produce more adverse effects on respiratory function in obese than in nonobese patients [7]. The concentration of supplemental $\mathrm{O}_{2}$ should be measured during general anesthesia to determine whether patients' $\mathrm{PaO}_{2}$ value is correct. However, the standard $\mathrm{PaO}_{2}$ value in obese patients and those undergoing oral and maxillofacial surgery in the supine position during general anesthesia is unknown.

The Broca-Katsura index is an index of obesity [8]-[10]. The modified Broca index is used for Japanese patients. This index is occasionally used to determine whether a patient is obese during the preoperative anesthetic evaluation. Very few studies have evaluated the $\mathrm{PaO}_{2}$ with respect to the Broca-Katsura index during general anesthesia. In this study, we evaluated the $\mathrm{PaO}_{2}$ with respect to the Broca-Katsura index in obese patients in the supine position during general anesthesia.

\section{Materials and Methods}

This retrospective study was approved by the Committee on Clinical Investigation for Human Research at Iwate Medical University.

From January 2001 to December 2013, we evaluated 472 patients aged $\geq 16$ years that underwent general anesthesia for oral and maxillofacial surgery and dental procedures in our department. None of the patients had a history of smoking or respiratory or cardiopulmonary disease. All patients had an American Society of Anesthesiologists physical status of I or II. Their anesthetic charts were retrospectively reviewed for age, height, weight, percent forced vital capacity (\%FVC), percent forced expiratory volume in $1 \mathrm{~s}\left(\% \mathrm{FEV}_{1.0}\right)$, and $\mathrm{PaO}_{2}$. First, the patients were divided into two groups by age: 16 to $<65$ years and $\geq 65$ years. Next, each group was divided according to the Broca-Katsura index. The Broca-Katsura index was used to determine whether a patient was obese and was calculated as follows:

Broca-Katsura index $(\%)=\{[$ weight in $\mathrm{kg}-($ height in $\mathrm{cm}-100)] \times 0.9\} /($ height in $\mathrm{cm}-100) \times 0.9$.

Patients aged $\geq 16$ to $<65$ years were divided into four groups [9]: Group A (normal weight; Broca-Katsura index of <20\%), Group B (mild obesity; Broca-Katsura index of $20 \%$ to $<40 \%$ ), Group C (moderate obesity; Broca-Katsura index of $40 \%$ to $<60 \%$ ), and Group D (severe obesity; Broca-Katsura index of $\geq 60 \%$ ). Patients aged $\geq 65$ years were divided into three groups: Group E (normal weight; Broca-Katsura index of $<20 \%$ ), Group F (mild obesity; Broca-Katsura index of $20 \%$ to $<40 \%$ ), and Group D (moderate obesity; Broca-Katsura index of $40 \%$ to $<60 \%$ ). Finally, Group B (mild obesity; Broca-Katsura index of $20 \%$ to $<40 \%$ ) was divided into five groups according to age: Group H (16 to $<26$ years old), Group I ( 26 to $<36$ years old), Group J (36 to $<46$ years old), Group K (46 to $<56$ years old), and Group L (56 to $<65$ years old).

Anesthesia was induced with intravenous propofol (1 - $2 \mathrm{mg} / \mathrm{kg}$ of ideal body weight) or thiopental sodium (3 - $5 \mathrm{mg} / \mathrm{kg}$ of ideal body weight). Muscle relaxation was provided by vecuronium bromide $(0.1 \mathrm{mg} / \mathrm{kg}$ of ideal body weight) or rocuronium bromide ( $0.8 \mathrm{mg} / \mathrm{kg}$ of ideal body weight). After tracheal intubation, anesthesia was maintained in almost all patients with sevoflurane (1\% - 2\%) and mechanical ventilation. Nitrous oxide gas was administered if necessary. The ventilatory settings were as follows: tidal volume, $8-10 \mathrm{~mL} / \mathrm{kg}$ of ideal body weight; respiratory rate, 10 - 12 breaths/min; peak airway pressure, $<20 \mathrm{~cm} \mathrm{H}_{2} \mathrm{O}$; positive end-expiratory pressure, $0 \mathrm{~cm} \mathrm{H} \mathrm{H}_{2} \mathrm{O}$; and inspiratory oxygen concentration, 33\%. After the patient had been stable for $30-60 \mathrm{~min}$ 
from the start of the operation, blood was drawn from the radial artery or dorsalis pedis artery and analyzed for blood gas concentrations.

Values are presented as mean \pm standard deviation. Statistical analysis was performed using SPSS, version 11.0 (SPSS, Inc., Chicago, IL, USA). Statistical analysis was performed by one-way analysis of variance followed by multiple-comparison testing among groups using the Sheffe test. Differences were considered statistically significant at a $p$ value of $<0.05$.

\section{Results}

All patients' characteristics and laboratory data according to age and Broca-Katsura index are presented in Table 1(a) and Table 1(b). In patients aged 16 to $<65$ years, there were no significant differences in age, height, \%FVC, or $\% \mathrm{FEV}_{1.0}$ among the four groups. However, there were significant differences in the body weight of Group D compared with Groups A and B, Group C compared with Groups A and B, and Group B compared with Groups A, $\mathrm{C}$, and $\mathrm{D}$. Furthermore, there were significant differences in the $\mathrm{PaO}_{2}$ of Group A compared with Groups $\mathrm{B}, \mathrm{C}$, and $\mathrm{D}$. The $\mathrm{PaO}_{2}$ decreased as the Broca-Katsura index increased (Table 1, Figure 1). In patients aged 65 to $<84$ years, there were no significant differences in age, $\% \mathrm{FVC}$, or $\% \mathrm{FEV}_{1.0}$ among the four groups. However, there were significant differences in the height of Group G compared with Groups E and F, in the body weight of Group E compared with Groups F and G, and in the $\mathrm{PaO}_{2}$ of Group E compared with Groups F and G (Table 1).

Table 1. (a) Patients' characteristics and laboratory data according to the Broca-Katsura index and age (16 to <65 years old); (b) Patients' characteristics and laboratory data according to the Broca-Katsura index and age (65 to <84 years old).

(a)

\begin{tabular}{ccccc}
\hline Broca-Katsura index (\%) & $0-20$ & $20-40$ & $40-60$ & $60-$ \\
$\mathrm{O}_{2}$ concentration (\%) & 33 & 33 & 33 & 33 \\
Group & $\mathrm{A}$ & $\mathrm{B}$ & $\mathrm{C}$ & $\mathrm{D}$ \\
Number (M:F) & $208(121: 87)$ & $109(63: 46)$ & $27(15: 12)$ & $5(5: 0)$ \\
Age (yrs) & $43.1 \pm 14.8$ & $45.6 \pm 13.7$ & $41.6 \pm 14.3$ & $41.1 \pm 16.0$ \\
Height (cm) & $163.7 \pm 8.8$ & $160.2 \pm 8.9$ & $159.6 \pm 19.2$ & $156.4 \pm 13.4$ \\
Weight (kg) & $58.5 \pm 9.9$ & $69.9 \pm 10.2^{* * *, \S}$ & $78.2 \pm 12.5^{* * *}$ & $86.6 \pm 23.1^{* * *}$ \\
\%FVC (\%) & $112.5 \pm 15.6$ & $109.8 \pm 15.8$ & $108.8 \pm 16.0$ & $112.8 \pm 6.8$ \\
$\mathrm{FEV}_{1.0} \%(\%)$ & $82.4 \pm 5.9$ & $82.1 \pm 6.0$ & $83.1 \pm 4.0$ & $86.2 \pm 2.4$ \\
PaO $_{2}(\mathrm{mmHg})$ & $165.7 \pm 25.6$ & $141.8 \pm 26.9^{*}$ & $132.7 \pm 22.2^{*}$ & $111.7 \pm 34.6^{*}$ \\
\hline
\end{tabular}

Data are presented as mean \pm standard deviation. ${ }^{*} p<0.05$ vs. Group A; ${ }^{*} p<0.05$ vs. Group B; ${ }^{*} p<0.05$ vs. Group C; ${ }^{\S} p<0.05$ vs. Group D

(b)

\begin{tabular}{cccc}
\hline Broca-Katsura index (\%) & $0-20$ & $20-40$ & $40-60$ \\
$\mathrm{O}_{2}$ concentration (\%) & 33 & 33 & 33 \\
Group & $\mathrm{E}$ & $\mathrm{F}$ & $\mathrm{G}$ \\
Number (M:F) & $101(58: 43)$ & $13(8: 5)$ & $75: 5)$ \\
Age (yrs) & $74.1 \pm 5.1$ & $73.9 \pm 5.6$ & $149.0 \pm 9.5$ \\
Height (cm) & $154.7 \pm 8.5$ & $151.6 \pm 8.2$ & $66.0 \pm 12.7^{\dagger}$ \\
Weight (kg) & $51.3 \pm 7.7$ & $60.9 \pm 9.2^{\dagger}$ & $97.3 \pm 13.1$ \\
\%FVC (\%) & $104.9 \pm 20.2$ & $102.3 \pm 13.1$ & $79.1 \pm 7.8$ \\
$\mathrm{FEV}_{1.0} \%(\%)$ & $78.1 \pm 5.1$ & $81.4 \pm 8.7^{\dagger}$ & $127.5 \pm 11.3^{\dagger}$ \\
$\mathrm{PaO}_{2}(\mathrm{mmHg})$ & $152.1 \pm 23.8$ & $130.6 \pm 26.7^{\dagger}$ & \\
\hline
\end{tabular}

Data are presented as mean \pm standard deviation. ${ }^{\dagger} p<0.05$ vs. Group $\mathrm{E}^{\ddagger}{ }^{\dagger} p<0.05$ vs. Group $\mathrm{F}$ 


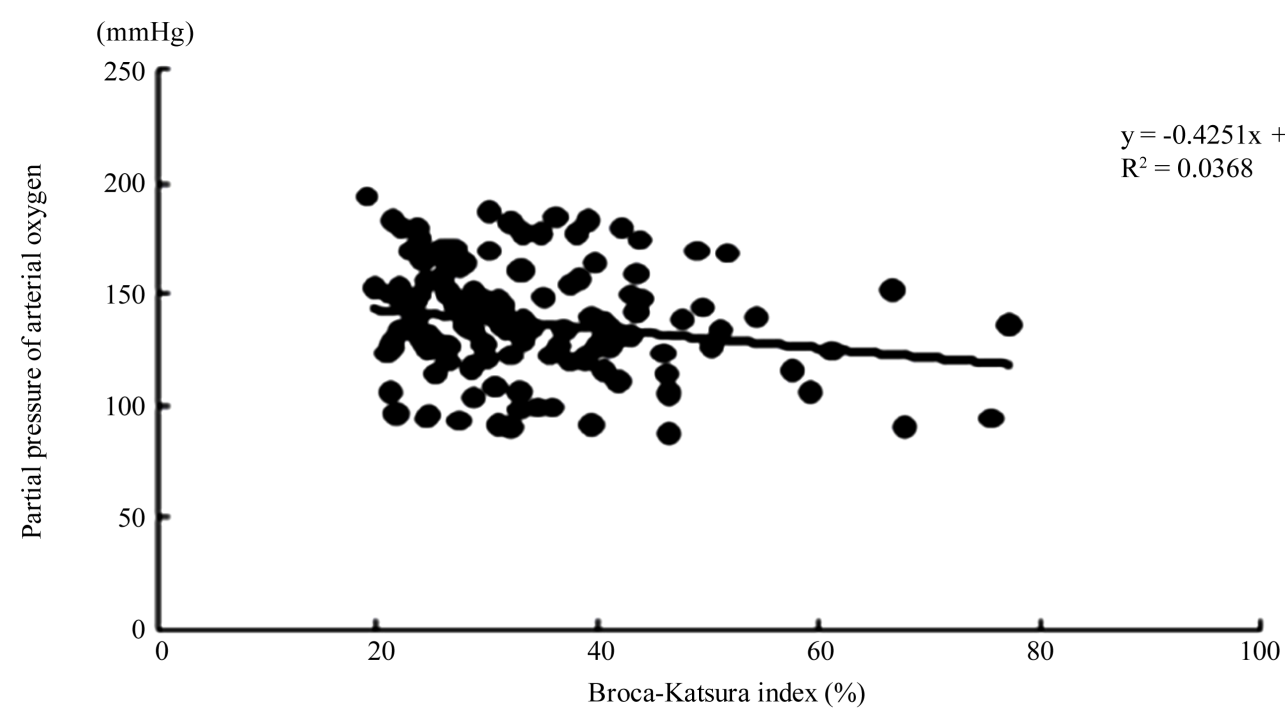

(a): Broca-Katsura index at 20 to $<80$ in group aged 16 to $<65$ years

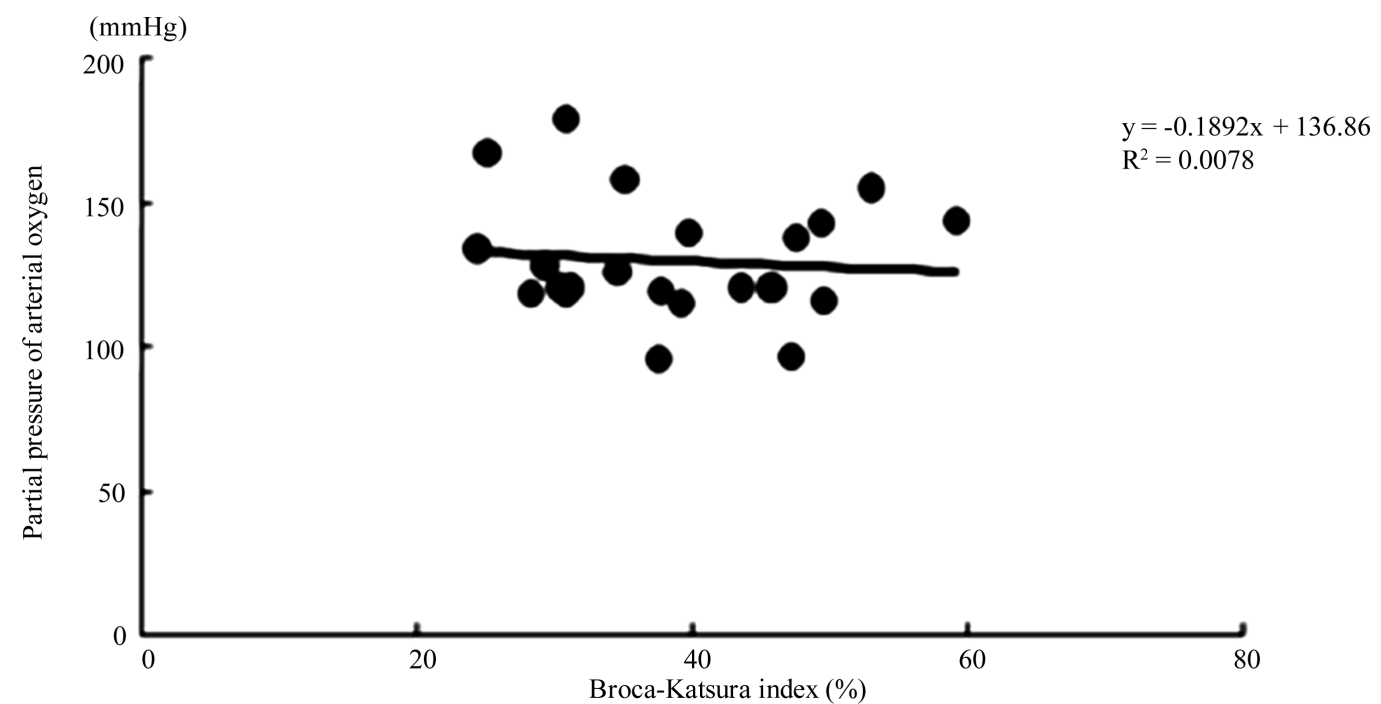

(b): Broca-Katsura index at 20 to $<60$ in group aged 65 to $<84$ years

Figure $1 . \mathrm{PaO}_{2}$ in the two main age groups according to the Broca-Katsura index at a $33 \%$ oxygen concentration. (a) Age of 16 to $<65$ years old. The mean $\mathrm{PaO}_{2}$ was $165.7 \pm 25.6 \mathrm{mmHg}$ at a Broca-Katsura index of $<20 \%, 141.8 \pm 26.9 \mathrm{mmHg}$ at a Broca-Katsura index of $20 \%$ to $<40 \%, 132.7 \pm 22.7 \mathrm{mmHg}$ at a Broca-Katsura index of $40 \%$ to $<60 \%$, and $111.7 \pm 34.6 \mathrm{mmHg}$ at a Broca-Katsura index of $\geq 60 \%$. (b) Age of $\geq 65$ years old. The mean $\mathrm{PaO}_{2}$ was $152.1 \pm 23.8 \mathrm{mmHg}$ at a Broca-Katsura index of $<20 \%, 130.6 \pm 26.7$ $\mathrm{mmHg}$ at a Broca-Katsura index of $20 \%$ to $<40 \%$, and $127.5 \pm 11.3 \mathrm{mmHg}$ at a Broca-Katsura index of $40 \%$ to $<60 \%$. These results demonstrate that the $\mathrm{PaO}_{2}$ tends to decrease with an increasing Broca-Katsura index in patients aged 16 to $<65$ years and $\geq 65$ years.

The characteristics and laboratory data of patients aged 16 to $<65$ years with a Broca-Katsura index of $20 \%$ $40 \%$ are presented in Table 2. There were no significant differences in the $\% \mathrm{FVC}$ or $\% \mathrm{FEV}_{1.0}$ among the five groups. However, there were significant differences in age among the five groups; in the height of Group L compared with Groups H, I, J, and K, of Group K compared with Groups H and J, and of Group I compared with Group H; in the body weight of Group L compared with Groups H, I, J, and K and of Group K compared with Groups $\mathrm{H}$ and J; and in the $\mathrm{PaO}_{2}$ of Group L compared with Groups $\mathrm{H}$ and I, of Group K compared with 
Table 2. Characteristics and laboratory data of patients aged 16 to $<65$ years old with a Broca-Katsura index of $20 \%$ to $\leq 40 \%$.

\begin{tabular}{cccccc}
\hline & aged 16 to $<26$ years & aged 26 to $<36$ years & aged 36 to $<46$ years & aged 46 to $<56$ years & aged 56 to $<65$ years \\
\hline Group & $\mathrm{H}$ & $\mathrm{I}$ & $\mathrm{J}$ & $\mathrm{K}$ & $\mathrm{L}$ \\
\hline Number (M:F) & $19(8: 10)$ & $11(7: 4)$ & $21(13: 8)$ & $35(21: 14)$ & $23(15: 8)$ \\
Age (yrs) & $19.9 \pm 3.7$ & $31.4 \pm 2.6^{*}$ & $41.2 \pm 2.7^{*, *}$ & $51.1 \pm 3.1^{*, *, \#}$ & $59.5 \pm 2.7^{*, *, \#, \S}$ \\
Height (cm) & $165.8 \pm 6.8$ & $163.2 \pm 5.9^{*}$ & $164.7 \pm 7.0$ & $159.1 \pm 8.6^{*, \#}$ & $154.4 \pm 8.4^{*, *, *, \S}$ \\
Weight (kg) & $77.2 \pm 8.2$ & $72.5 \pm 7.7$ & $75.1 \pm 7.5$ & $68.0 \pm 9.7^{*, \#}$ & $63.7 \pm 9.3^{*, *, \#, \S}$ \\
\%FVC (\%) & $114.3 \pm 19.4$ & $113.0 \pm 18.9$ & $113.0 \pm 12.9$ & $113.2 \pm 11.5$ & $102.5 \pm 16.6$ \\
$\mathrm{FEV}_{1.0} \%(\%)$ & $82.7 \pm 6.5$ & $85.1 \pm 4.3$ & $82.4 \pm 4.5$ & $80.9 \pm 5.4$ & $84.0 \pm 6.4$ \\
$\mathrm{PaO}_{2}(\mathrm{mmHg})$ & $165.0 \pm 22.3$ & $156.4 \pm 18.9$ & $139.3 \pm 27.1^{*}$ & $131.7 \pm 22.6^{*, *}$ & $130.9 \pm 21.0^{*, *}$ \\
\hline
\end{tabular}

Data are presented as mean \pm standard deviation. ${ }^{*} p<0.05$ vs. Group H; ${ }^{*} p<0.05$ vs. Group I; ${ }^{*} p<0.05$ vs. Group J; ${ }^{\S} p<0.05$ vs. Group K.

Groups $\mathrm{H}$ and I, and of Group J compared with Group $\mathrm{H}$ (Table 2). The mean of $\mathrm{PaO}_{2}$ tended to increase with increasing age in patients aged 16 to $<65$ years and with a Broca-Katsura index of 20\% - 40\%.

In group at age of 16 to $<65$ years with a Broca-Katsura index of $20 \%$ to $<80 \%$ (Figure 1 (a)), the correlation between $\mathrm{PaO}_{2}$ and Broca-Katsura index (20\% to <80\%); $\mathrm{PaO}_{2}$ linearly decreased with increasing Broca-Katsua index $(R=0.191 ; p<0.05)$ (Figure 1(a)), and there was a not correlation between the two. In group at age of 65 to $<84$ years with Broca-Katsura index at 20\% to $<60 \%$ (Figure 1(b)), the correlation between $\mathrm{PaO}_{2}$ and Broca-Katsura index (20\% to $<60 \%) ; \mathrm{PaO}_{2}$ linearly decreased with increasing Broca-Katsua index $(R=0.0881 ; p<$ 0.05), and there was a not correlation between the two. In groups with Broca-Katsura index at $20 \%$ to $<40 \%$ (Figure 2(a)), the correlation between $\mathrm{PaO}_{2}$ and age; $\mathrm{PaO}_{2}$ linearly decreased with increasing age $(R=0.3761 ; p$ $<0.05$ ), and there was a slight correlation between the two. And in groups with Broca-Katsura index at $40 \%$ to $<$ $60 \%$ (Figure 2(b)), the correlation between $\mathrm{PaO}_{2}$ and age; $\mathrm{PaO}_{2}$ linearly decreased with increasing age $(R=$ $0.3481 ; p<0.05)$, and there was a slight correlation between the two.

\section{Discussion}

In this study, we found out two important issues. The standard $\mathrm{PaO}_{2}$ in obese patients in the supine position during general anesthesia is determined with respect to the Broca-Katsura index. The mean $\mathrm{PaO}_{2}$ tends to decrease with an increasing Broca-Katsura index in patients aged 16 to $<65$ years and 65 to $<84$ years.

First, the standard $\mathrm{PaO}_{2}$ in obese patients in the supine position during general anesthesia is determined with respect to the Broca-Katsura index. In the supine position, it is thought that impaired arterial oxygenation during general anesthesia is mainly attributable to the development of intrapulmonary shunting (atelectasis) and deterioration in the ventilation-perfusion relationship [6] [11] [12]. Loss of respiratory muscle tone associated with anesthetic induction and muscle paralysis presumably decrease the transverse chest area and force the diaphragm to move cephalad, leading to reduction in the functional residual capacity (FRC) and compression of dependent lung tissue (compression atelectasis) [13] [14]. Additionally, general anesthesia in the supine position induces atelectasis formation, a reduction in lung volume, and mechanical respiratory impairment that may be associated with gas exchange abnormalities [3]. Physiological pulmonary derangements in obese adults include decreases in the FRC, FVC, and $\mathrm{FEV}_{1.0}$ [15]. A linear relationship between increases in the body mass index (BMI) and decreases in the FRC [16]. Increases in abdominal mass and intra-abdominal pressure are expected with increases in the BMI [17]. The gravitational intra-abdominal pressure gradient likely increases with an increased load especially in the most dependent lung regions, resulting in cephalad displacement of the diaphragm and reduction in the passive movements of its dependent portions [18] [19]. Oxygenation decreased with an increasing BMI and that the main cause of this decrease was likely related to the reduction in FRC. Although the mechanisms of FRC reduction and atelectasis formation during general anesthesia are not understood, it is thought that the major causes of the decrease in oxygenation with an increasing Broca-Katsura index in the present study are likely related to reduction in the FRC and atelectasis formation induced by general anesthesia. We believe that these data can help to predict the outcome of the $\mathrm{PaO}_{2}$ value in obese patients in the supine position during general anesthesia. 


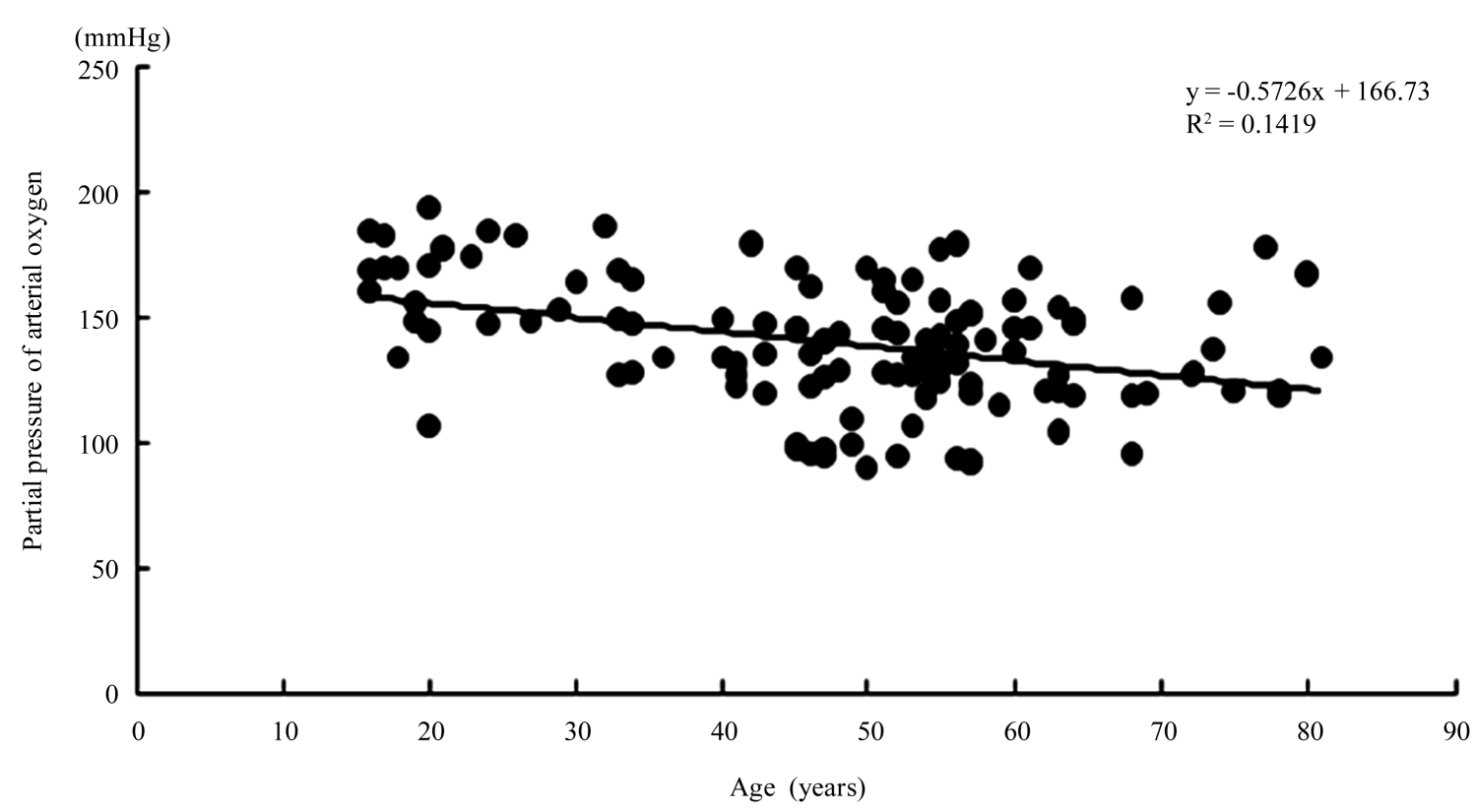

(a): Broca-Katsura index at 20 to $<40$

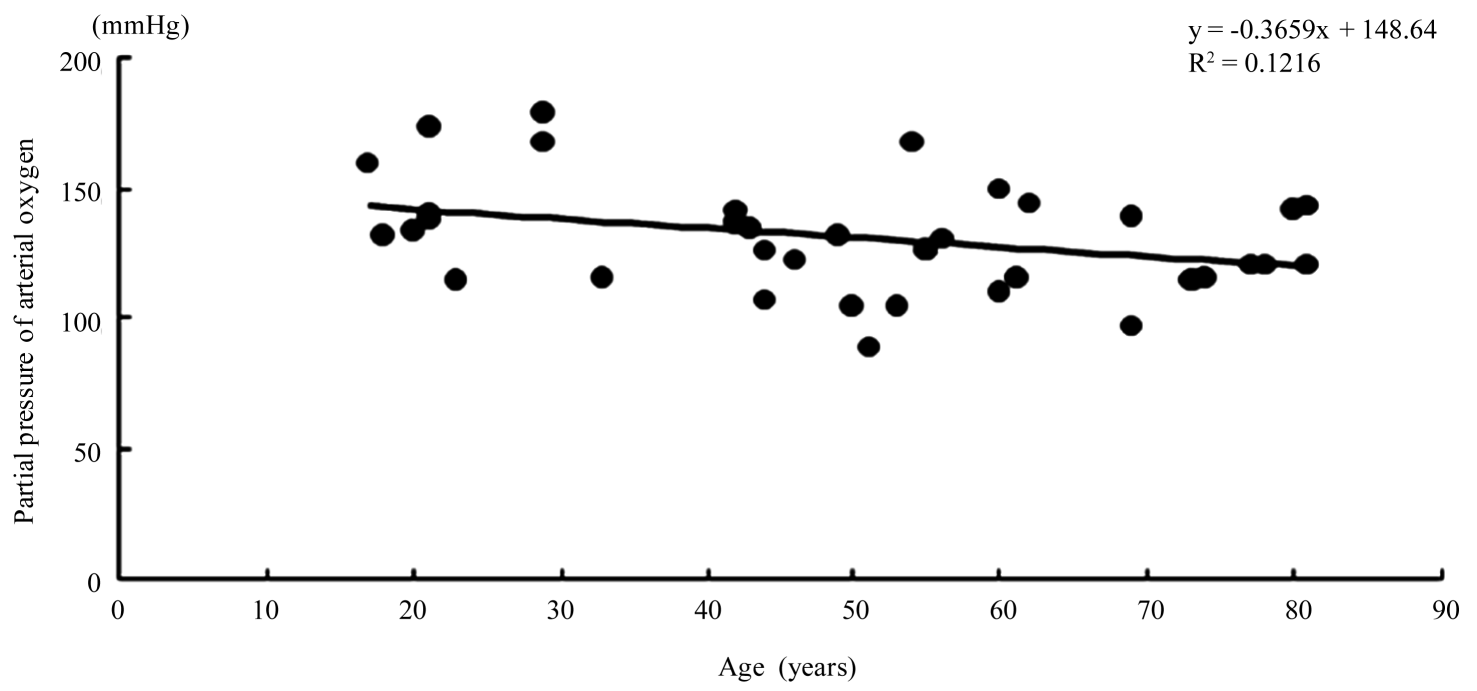

(b): Broca-Katsura index at 40 to $<60$

Figure 2. $\mathrm{PaO}_{2}$ in the various age groups according to a Broca-Katsura index of $20 \%$ to $<40 \%$ at a $33 \%$ oxygen concentration. The mean $\mathrm{PaO}_{2}$ was $165.0 \pm 22.3 \mathrm{mmHg}$ in patients aged 16 to $<26$ years, $156.4 \pm 18.9 \mathrm{mmHg}$ in patients aged 26 to $<36$ years, $139.7 \pm 27.1 \mathrm{mmHg}$ in patients aged 36 to $<46$ years, $131.7 \pm 22.6 \mathrm{mmHg}$ in patients aged 46 to $<56$ years, and $130.9 \pm 21.0 \mathrm{mmHg}$ in patients aged 56 to $<65$ years. The $\mathrm{PaO}_{2}$ tended to decrease with age in patients aged 16 to $<65$ years with a Broca-Katsura index of $20 \%$ to $<40 \%$.

Second, the mean $\mathrm{PaO}_{2}$ tends to decrease with an increasing Broca-Katsura index in patients aged 16 to $<65$ years and 65 to $<84$ years. In this study, when the mean $\mathrm{PaO}_{2}$ was evaluated by Broca-Katsura index, the mean $\mathrm{PaO}_{2}$ tended to decrease with an increasing Broca-Katsura index and there were significant differences among groups (Table 1, Table 2). But there was not a correlation between $\mathrm{PaO}_{2}$ and Broca-Katsura index $(20 \%$ to $<80 \%$ ) in group at age of 16 to $<65$ or Broca-Katsura index at $20 \%$ to $<60 \%$ in group at age of 65 to $<84$ since the correlation between $\mathrm{PaO}_{2}$ and Broca-Katsura index was low $(\mathrm{R}<0.200)$. The $\mathrm{PaO}_{2}$ might linearly decrease with increasing age with Broca-Katsura index at $20 \%$ to $<40 \%$ or at $40 \%$ to $<60 \%$ since there was a slight correlation between $\mathrm{PaO}_{2}$ and age (Figure 2(a), Figure 2(b)). Nevertheless, we believe that these data can help to 
predict the outcome of the $\mathrm{PaO}_{2}$ value in obese patients in the supine position during general anesthesia.

\section{Conclusion}

The standard $\mathrm{PaO}_{2}$ in obese patients in the supine position during general anesthesia is determined with respect to the Broca-Katsura index and the mean $\mathrm{PaO}_{2}$ tends to decrease with an increasing Broca-Katsura index in patients aged 16 to $<65$ years old and 65 to $<84$ years old. Though there was not a correlation between $\mathrm{PaO}_{2}$ and Broca-Katsura index, there was a slight correlation between $\mathrm{PaO}_{2}$ and age. We believe that the data provide reliable information on the value of $\mathrm{PaO}_{2}$ and are clinically useful for management of anesthesia.

\section{Acknowledgements}

None.

\section{Conflicts of Interest}

Kenichi Satoh, Mami Chikuda, Ayako Ohashi, Miho Kumagai, Akiyoshi Kuji, and Shigeharu Joh have no conflicts of interest.

\section{References}

[1] Smith, H.L., Melderum, D.J. and Brennaan, L.J. (2002) Childhood Obesity: A Challenge for the Anesthetist? Pediatric Anesthesia, 12, 750-761. http://dx.doi.org/10.1046/j.1460-9592.2002.00781.x

[2] Jenese, H.G., Dubin, S.A., Silverstein, P.I. and O’Leary-Escolas, U. (1991) Effect of Obesity on Safe Duration of Apnea in Anesthetized Humans. Anesthesia \& Analgesia, 72, 89-93. http://dx.doi.org/10.1213/00000539-199101000-00016

[3] Kabon, B., Nagele, A., Reddy, D., Eagon, C., Fleshman, J.W., Sessler, D.I. and Kurz, A. (2004) Obesity Decreases Perioperative Tissue Oxygenation. Anesthesiology, 100, 274-280. http://dx.doi.org/10.1097/00000542-200402000-00015

[4] Rehder, K. and Marsh, H.M. (1986) Respiratory Mechanics during Anesthesia and Mechanical Ventilation. In: Macklem, P.T. and Mead, J., Eds., Handbook of Physiology: The Respiratory System, American Physiological Society, Bethesda, 737-752.

[5] Hedenstierna, G., Stranberg, A., Brismar, B., Lundquist, H., Svensson, L. and Tokics, L. (1985) Functional Residual Capacity, Thoracoabdominal Dimensions, and Central Blood Volume during General Anesthesia with Muscle Paralysis and Mechanical Ventilation. Anesthesiology, 62, 247-254. http://dx.doi.org/10.1097/00000542-198503000-00007

[6] Tokics, L., Hedenstiema, G., Strandberg, A., Brismar, B. and Lundquist, H. (1987) Lung Collapse and Gas Exchange during General Anesthesia: Effects of Spontaneous Breathing, Muscle Paralysis, and Positive End-Expiratory Pressure. Anesthesiology, 66, 157-167. http://dx.doi.org/10.1097/00000542-198702000-00009

[7] Standberg, A., Tokics, L., Brismar, B., Lundquist, H. and Hedenstierna, G. (1987) Constitutional Factors Promoting Development of Atelectasis during Anaesthesia. Acta Anaesthesiologica Scandinavica, 31, 21-24. http://dx.doi.org/10.1111/j.1399-6576.1987.tb02513.x

[8] Omura, M., Zinno, S., Harada, T. and Inoue, N. (1993) Evaluation of Validity of five Weight-Height Obesity Indices. Fukuoka Igaku Zassi (Hukuoka Acta Medica), 84, 305-310.

[9] Nishida, M. and Funahashi, T. (2009) Validity of Indices (BMI, Rohrer Index, Broca Method) for Assessment of Obesity. Nihon Rinsho, 67, 301-306.

[10] Park, W. and Park, S. (2013) Body Shape Analyses of Large Persons in South Korea. Ergonomics, 56, 692-706. http://dx.doi.org/10.1080/00140139.2012.752529

[11] Yoshino, J., Akata, T. and Takahashi, S. (2003) Intraoperative Changes in Arterial Oxygenation during Volume-Controlled Mechanical Ventilation in Modestly Obese Patients Undergoing Laparotomies with General Anesthesia. Acta Anaesthesiologica Scandinavica, 47, 742-750. http://dx.doi.org/10.1034/j.1399-6576.2003.00147.x

[12] Rothen, H.U., Sporre, B., Engberg, G., Wegenius, G. and Hedenstierna, G. (1998) Airway Closure, Atelectasis and Gas Exchange during General Anaesthesia. British Journal of Anaesthesia, 81, 681-686. http://dx.doi.org/10.1093/bja/81.5.681

[13] Hedenstierna, G., Tokics, L., Lundquist, H., Andersson, T., Strandberg, A. and Bristmar, B. (1994) Phrenic Nerve Stimulation during Halothane Anesthesia. Effects of Atelectasis. Anesthesiology, 80, 751-760.

http://dx.doi.org/10.1097/00000542-199404000-00006

[14] Benumof, J.L. (2000) Respiratory Physiology and Respiratory Function during Anesthesia. In: Miller, R.D., Ed., 
Anesthesia, Churchil Livengstone, Philadelphia, 578-618.

[15] Setzer, N. and Saade, E. (2007) Childhood Obesity and Anesthetic Morbidity. Pediatric Anesthesia, 17, 321-326. http://dx.doi.org/10.1111/j.1460-9592.2006.02128.x

[16] Pelosi, P., Croci, M., Ravagnan, .I, Tredici, S., Pedoto, A., Lissoni, A. and Gattinoni, L. (1998) The Effects of Body Mass on Lung Volumes, Respiratory Mechanics, and Gas Exchange during General Anesthesia. Anesthesia \& Analgesia, 87, 654-660. http://dx.doi.org/10.1097/00000539-199809000-00031

[17] Pelosi, P., Croci, M., Ravagnan, I., Cerisara, M., Vicardi, P., Lissoni, A. and Gattinoni, L. (1997) Respiratory System Mechanics in Sedated, Paralyzed, Morbidly Obese Patients. Journal of Applied Physiology, 82, 811-818.

[18] Hedenstierna, G., Santesson, J. and Norlamder, O. (1976) Airway Closure and Distribution of Inspired Gas in the Extremely Obese, Breathing Spontaneously and during Anaesthesia with Intermittent Positive Pressure Ventilation. Acta Anaesthesiologica Scandinavica, 20, 334-342. http://dx.doi.org/10.1111/j.1399-6576.1976.tb05047.x

[19] Rothen, H.U., Sporre, B., Engberg, G., Wegenius, G. and Hedenstierna, G. (1995) Reexpansion of Atelectasis during General Anaesthesia May Have a Prolonged Effect. Acta Anaesthesiologica Scandinavica, 39, 118-125. http://dx.doi.org/10.1111/j.1399-6576.1995.tb05602.x

\section{Abbreviations}

\%FVC: \% forced vital capacity;

$\mathrm{FEV}_{1.0} \%$ : forced expiratory volume 1.0 second \%;

$\mathrm{PaO}_{2}$ : arterial partial pressure of oxygen. 